ORIGINAL ARTICLE

\title{
Intestinal permeability is increased in bronchial asthma
}

\author{
Z Hijazi, A M Molla, H Al-Habashi, W M R A Muawad, A M Molla, P N Sharma
}

Arch Dis Child 2004;89:227-229. doi: 10.1136/adc.2003.027680

See end of article for authors' affiliations ....................

Correspondence to: Prof. Z Hijazi, Department of Paediatrics, Faculty of Medicine, Kuwait

University, PO Box 24923,

Kuwait 13110;

zeinat@hsc.kuniv.edu.kw

Accepted 22 July 2003

\begin{abstract}
Background: Increased intestinal permeability has been reported in one study of adult asthmatics.
Aim: To determine whether children with asthma have altered intestinal permeability.

Methods: Thirty two asthmatic children, and 32 sex and age matched controls were recruited. The dual sugar (lactulose and mannitol) test was used to evaluate intestinal permeability, and the percentage of ingested lactulose (L) and mannitol $(M)$ in the urine, and the L:M ratio were determined. All patients were skin prick tested for common aeroallergens, and specific lgE to some food items was determined.

Results: The median value of $L$ in asthmatic children (2.29, IQR 0.91-4.07) was significantly higher than that in controls $(0.69$, IQR $0.45-1.08)$, and that of $M$ was almost similar. The ratio L:M was significantly higher in asthmatic children (0.20, IQR 0.11-0.40) than in controls (0.06, IQR 0.04-0.09). Intestinal permeability did not correlate with eczema, inhaled steroids, positive skin prick test to aeroallergens, or severity of asthma.

Conclusions: Intestinal permeability is increased in children with asthma, suggesting that the whole mucosal system may be affected.
\end{abstract}

A possible relation between asthma and the gastrointestinal tract is an area of increasing interest. Food challenge can elicit wheezing in some children with asthma. ${ }^{1}$ Gastrointestinal symptoms are common in children with asthma, ${ }^{2}$ and duodenal histological changes and cytokine production mimicking those observed in bronchial asthma, have been shown. ${ }^{3}$ Asthma is a $\mathrm{T}$ lymphocyte mediated inflammatory disease of the bronchus, ${ }^{4}$ and it has been suggested that the whole mucosal immune system might be involved, with activated $\mathrm{T}$ lymphocytes migrating from one mucosal site to another. ${ }^{5}{ }^{6}$ Walleret and colleagues ${ }^{7}$ have recently shown an airway-like inflammation of the minor salivary glands, and Benard and colleagues ${ }^{6}$ showed increased intestinal permeability in adults with bronchial asthma. To our knowledge, this work has not been reproduced in adult asthmatics, and no similar study has so far been conducted in children with asthma.

We report the first study designed to evaluate intestinal permeability in asthmatic children, by using the dual sugar test, as an indirect measure of integrity of the intestinal mucosa.

\section{METHODS \\ Patients}

The study subjects were recruited from the Paediatric Asthma clinic at Mubarak Al-Kabeer hospital (the main teaching hospital in Kuwait), between January 2001 and June 2002. These patients fulfilled the International Consensus Criteria for the diagnosis of asthma, ${ }^{8}$ and had the disease for no less than one year. Exclusion criteria included evidence of digestive disease, food allergy, or any other condition associated with increased intestinal permeability, such as cystic fibrosis, coeliac disease, rheumatological disease, or use of non-steroidal anti-inflammatory drugs, and those with positive skin test against common food allergens (see below). The control subjects were children attending a general paediatric clinic, their healthy siblings, and friends. The control subjects fulfilled the same exclusion criteria as the patients, and never had asthma or eczema.

Written informed consent was obtained from the parents of all subjects in the study. The Departmental Research
Committee approved the study in terms of ethics and scientific merits.

\section{Asthma severity}

Asthma was divided into grades I-IV (I being the mildest and IV the most severe). Grading was based on events that took place over the past six months; including day and night symptoms, effect of asthma on daily activity, use of steroids, and peak expiratory flow rate in children $\geqslant 6$ years of age, and as defined by the International Paediatric Consensus Group. ${ }^{9}$

\section{Skin testing}

Sensitivity of patients to common aeroallergens (house dust mite, Dermatophagoidespteronyssinus and D farnae mites; grass, tree, and weed pollens; Aspergillusfumigatus; Alternaria, Cladosporium (Stallergenes, Paris)) was evaluated by skin prick tests (SPT) according to standardised protocol..$^{10}$

\section{Allergen specific $\lg E$}

Allergen specific serum IgE for the same aeroallergens as well as food allergens (egg white, fish, peanuts, cows' milk) was determined using the Pharmania CAP-RAST test as described previously; ${ }^{11}$ those with positive tests for food allergy were excluded from the study.

\section{Measurement of intestinal permeability}

The dual sugar test was used in this study. After an overnight fast, children ingested $10 \mathrm{ml}$ solution containing 1 gram lactulose (non-metabolised, high molecular weight sugar) and 1 gram mannitol (absorbable, low molecular weight sugar). Liberal intake of water was allowed after 30 minutes, and food after five hours. Urine was collected for a total of five hours, after ingestion of sugars, in a container with a few drops of $20 \%$ chlorohexidine as a preservative; urine volume was recorded. A $10 \mathrm{ml}$ aliquot of urine was stored at $-20^{\circ} \mathrm{C}$ until analysis. Total urinary excretion of mannitol and lactulose was estimated according to the methods described previously, ${ }^{12}$ but modified for the autoanalyser

Abbreviations: L, lactulose; M, mannitol; SPT, skin prick test 
COBASMIRA $^{14}$. The results were expressed as a percentage of the ingested dose (lactulose $\mathrm{mg} \%$ (L) and mannitol $\mathrm{mg} \%$ (M)). The ratio L:M was calculated.

\section{Statistical analysis}

Results are presented as mean (SE) for age, weight, and height; the values were compared between patients and the control group using the $t$ test for two independent samples. The values for different clinical variables are shown as median and interquartile range (25-75th centile) for each group as these data were not normally distributed. Hence, the groups were compared using the non-parametric Kolmogorov-Smirnov $\mathrm{Z}$ test and median test, in case of severity groups. The $\chi^{2}$ test was applied to test the differences in proportions between patients and controls. A probability level of $p<0.05$ was considered significant. Statistical software (SPSS version 11.0) was used for analysis.

\section{RESULTS}

Thirty two asthmatic children and 32 control subjects, aged 5-12 years, were included in the study. Table l shows sex, mean age, weight, height, and consanguinity. Mean age and gender in both groups were similar. However, weight and height were slightly higher in the control group. Consanguinity was high among parents of patients as well as controls.

Twelve patients had eczema (previous in nine and concurrent in three). The mean duration of symptoms was 4.1 (0.12) years (range 1.0-8.1 years). In seven patients asthma was of grade I severity, seven grade II, ten grade III, and eight grade IV. Twenty one patients were on inhaled steroids; none were receiving oral steroids or skin preparation containing steroids. Skin prick test was positive in 26 patients, of whom 19 were positive to more than one allergen; six patients were negative to all allergens used in the study.

The median value of the percentage of the ingested lactulose recovered from the urine of asthmatic children, was significantly higher than that for the controls $(p<0.002)$, while that for mannitol was more or less similar (table 2). The ratio of L:M was significantly higher in children with asthma compared to controls $(p<0.001)$ (table 2$)$. The median values of L, M, and L:M of patients with or without inhaled steroids were similar (table 3 ). The median value of L:M for patients with eczema and those without were also not found significant (table 3). Patients with positive SPT had lower mean values than those who were negative, but the difference was not statistically significant. Intestinal permeability did not correlate with severity of asthma (table 4).

Table 1 Characteristics of patients and controls

\begin{tabular}{|c|c|c|c|}
\hline & Patients ( $n=32$ ) & Controls ( $n=32$ ) & $p$ value \\
\hline Males & 21 & 18 & NS \\
\hline Females & 11 & 14 & NS \\
\hline \multicolumn{4}{|l|}{ Age } \\
\hline $5-8$ years & 19 & 17 & NS \\
\hline $9-12$ years & 13 & 15 & NS \\
\hline Mean (SE) & $8.5(0.18)$ & $8.1(0.21)$ & NS \\
\hline \multicolumn{4}{|c|}{$\begin{array}{l}\text { Weight }(\mathrm{kg}) \text {, mean } \\
\text { (SE) }\end{array}$} \\
\hline $5-8$ years & $22.0(0.21)$ & $23.8(0.37)$ & 0.001 \\
\hline $9-12$ years & $34.5(0.19)$ & $35.6(0.21)$ & 0.018 \\
\hline \multicolumn{4}{|c|}{$\begin{array}{l}\text { Height }(\mathrm{cm}) \text {, mean } \\
(\mathrm{SE})\end{array}$} \\
\hline $5-8$ years & $120.0(0.39)$ & $121.2(0.21)$ & 0.049 \\
\hline $9-12$ years & $128.4(0.05)$ & $129.0(0.04)$ & 0.001 \\
\hline Consanguinity & $13(40.6 \%)$ & $12(37.5 \%)$ & NS \\
\hline
\end{tabular}

Table 2 Percentage of lactulose (L) and mannitol (M) recovered from the urine and $L: M$ ratio in asthmatic patients and control subjects

\begin{tabular}{llll}
\hline & Patients $(\mathbf{n}=\mathbf{3 2})$ & Controls $(\mathbf{n}=32)$ & p value \\
\hline Volume of urine (I) $0.25(0.11-0.45)$ & $0.15(0.08-0.27)$ & NS \\
$L$ & $2.29(0.91-4.07)$ & $0.69(0.45-1.08)$ & 0.002 \\
$M$ & $11.82(5.70-15.65)$ & $11.28(6.38-16.82)$ & $N S$ \\
$L: M$ & $0.20(0.11-0.40)$ & $0.06(0.04-0.09)$ & 0.001 \\
\hline \multirow{2}{*}{ Results expressed as median (interquartile range). }
\end{tabular}

\section{DISCUSSION}

Histological examination of the small intestinal biopsy specimens remains the gold standard for the evaluation of the small intestinal mucosa. However, for various reasons most workers now prefer to use non-invasive techniques. Measurement of the differential absorption of monosaccharides of different molecular size, after an oral dose, has gained popularity in recent years. ${ }^{15}$ In our study, two sugars, one with a smaller molecular size (mannitol) and another with a larger molecular size (lactulose) were chosen. The ratio of the urinary excretion of the lactulose over mannitol was determined in the urine collected for five hours after the oral dose. Determination of the ratio of the sugars makes the test more sensitive. It eliminates potential confounding factors such as defects in collection, gastric retention, transit time, and renal clearance, ${ }^{16}$ as the physiological parameters affect the sugars equally but do not affect the ratio. The intestinal permeability of the larger molecules like lactulose is increased in case of damage of the intestinal mucosa, but for the smaller molecules like mannitol, remains unchanged or

Table 3 Percentage of lactulose (L) and mannitol (M) recovered from the urine and $L: M$ ratio in asthmatic patients on inhaled steroids, with eczema, positive SPT, and those without

\begin{tabular}{|c|c|c|c|}
\hline & Category of patients & & $p$ value \\
\hline & Steroids $(n=11$ ) & No steroids ( $n=21$ ) & \\
\hline L & $2.16(0.91-4.08)$ & $2.42(0.86-4.13)$ & NS \\
\hline$M$ & $11.74(4.61-17.53)$ & $12.20(6.50-15.50)$ & NS \\
\hline \multirow[t]{2}{*}{$L: M$} & $0.22(0.11-0.43)$ & $0.17(0.07-0.32)$ & NS \\
\hline & With eczema $(n=12)$ & No eczema $(n=20)$ & \\
\hline L & $2.36(0.82-3.61)$ & $2.22(0.94-4.33)$ & NS \\
\hline$M$ & $15.06(8.14-17.54)$ & $11.37(5.13-14.58)$ & NS \\
\hline \multirow[t]{2}{*}{ L:M } & $0.16(0.08-0.38)$ & $0.22(0.11-0.44)$ & NS \\
\hline & Positive SPT $(n=26)$ & Negative SPT $(n=6)$ & \\
\hline $\mathrm{L}$ & $2.09(0.89-4.16)$ & $2.71(0.95-6.78)$ & NS \\
\hline$M$ & $11.72(6.23-15.50)$ & $14.85(3.04-18.91)$ & NS \\
\hline L:M & $0.18(0.10-0.38)$ & $0.46(0.19-0.99)$ & NS \\
\hline
\end{tabular}

Table 4 Percentage of lactulose (L) and mannitol (M) recovered from the urine of patients and $L: M$ ratios according to severity of disease ( $n=32$ patients)

\begin{tabular}{|c|c|c|c|c|c|}
\hline & \multicolumn{4}{|l|}{ Severity } & \multirow{2}{*}{$\begin{array}{l}\mathrm{P} \\
\text { value }\end{array}$} \\
\hline & $I(n=7)$ & II $(n=7)$ & III $(n=10)$ & IV $(n=8)$ & \\
\hline L & $\begin{array}{l}1.02 \\
(0.86-4.26)\end{array}$ & $\begin{array}{l}2.67 \\
(1.32-3.90)\end{array}$ & $\begin{array}{l}2.22 \\
(1.01-2.66)\end{array}$ & $\begin{array}{l}3.73 \\
(0.41-4.91)\end{array}$ & NS \\
\hline M & $\begin{array}{l}11.74 \\
(3.79-23.00)\end{array}$ & $\begin{array}{l}15.50 \\
(3.30-17.55)\end{array}$ & $\begin{array}{l}11.95 \\
(9.94-15.27)\end{array}$ & $\begin{array}{l}9.43 \\
(2.92-14.96)\end{array}$ & NS \\
\hline L:M & $\begin{array}{l}0.15 \\
(0.09-0.40)\end{array}$ & $\begin{array}{l}0.24 \\
(0.20-0.83)\end{array}$ & $\begin{array}{l}0.14 \\
(0.06-0.25)\end{array}$ & $\begin{array}{l}0.29 \\
(0.13-0.54)\end{array}$ & N.S \\
\hline
\end{tabular}


decreased. ${ }^{12}$ Therefore, slight changes in the excretion of both sugars result in significant changes in the ratio.

In this study, the dual sugar test has shown a significant increase of intestinal permeability in children with asthma compared with controls $(p<0.001)$. Among the asthmatic children, increased intestinal permeability did not correlate with asthma severity, treatment with inhaled steroids, associated eczema, or allergy as indicated by positive SPT. Although many investigators have studied the permeability of nasal and respiratory mucosa in atopy, ${ }^{17}$ reports of evaluation of the intestinal permeability in bronchial asthma are scarce. To our knowledge, the only study in the literature on intestinal permeability in asthma is that of Benard and colleagues $^{6}$ in France. They showed increased intestinal permeability in adult patients with bronchial asthma compared with patients with chronic obstructive pulmonary disease and healthy control subjects. In their study, they used radioactive material (CrEDTA) which was administered orally, and estimated its urinary recovery.

The mechanisms responsible for increased intestinal permeability in asthma remain unclear. However, gastrointestinal abnormalities have been reported in patients with asthma. Duodenal histological changes mimicking those observed in bronchial mucosa have been shown. ${ }^{318}$ Nevertheless, in asthma, it is not yet known whether increased intestinal permeability is correlated with gut inflammatory infiltrate.

Our study showed that increased intestinal permeability was not correlated with asthma severity and was not affected by inhaled steroids. Similar findings were reported by Benard and colleagues ${ }^{6}$ who also found no correlation between serum IgE level, blood eosinophilia, and intestinal permeability.

Increased intestinal permeability has been shown in adult patients with eczema. ${ }^{19}$ In addition, minor morphological abnormalities of the gastrointestinal tract have been shown in children with atopy. ${ }^{20}$ In our study, increased intestinal permeability in the asthmatic children, was similar in those with and without eczema. It remains unclear whether histological and functional changes are associated primarily with asthma, eczema, or the atopic status in general. Alternatively, it may be that the difference in the phenotype of atopic patients may be related to differential expression of relevant cytokines and/or their receptors in different tissues. Our findings lend support to the view that gastrointestinal abnormalities are common in children with all atopic diseases. ${ }^{20}$ Whether increased intestinal permeability is a primary inherited abnormality in patients with asthma or atopy remains to be elucidated, as well as the functional implications of such abnormalities.

In conclusion, this study has for the first time shown increased intestinal permeability in children with bronchial asthma. Intestinal permeability did not correlate with the severity of asthma, treatment with steroids, or eczema. This lends further support to the view that the whole mucosal immune system may be involved in such patients. The functional implications of such findings need to be elucidated.

\section{Authors' affiliations}

Z Hijazi, A M Molla, W M R A Muawad, P N Sharma, Faculty of Medicine, Kuwait University, Kuwait

H Al-Habashi, Paediatric Department, Mubarak AlKabeer Hospital, Kuwait

A M Molla, Department of Biochemistry, Laboratory Medical Science, Faculty of Allied Health Science and Nursing, Kuwait University, Kuwait

\section{REFERENCES}

1 Novembre E, de Mrtino M, Vierucci A. Foods and respiratory allergy. J Allergy Clin Immunol 1988;81:1059-65

2 Caffarelli C, Deriu FM, Terzi V, et al. Gastrointestinal symptoms in patients with asthma. Arch Dis Child 2000;82:131-5.

3 Wallaert B, Destremaux P, Copin MC, et al. Immunoreactivity for interleukin 3 and 5 and granulocyte/macrophage colony-stimulating factor of intestinal mucosa in bronchial asthma. J Exp Med 1995;182:1897-904.

4 Diukanovic R, Roche WR, Wilson JW, et al. Mucosal inflammation in asthma. Am Rev Respir Dis 1990;142:434-57.

5 Mestecky J, McGhee JR, Michalek SM, et al. Concept of the local and common mucosal immune response. Adv Exp Med Biol 1978;107:185-92.

6 Benard A, Desreumeaux P, Huglo D, et al. Increased intestinal permeability in bronchial asthma. J Allergy Clin Immunol 1996;97:1 173-8.

7 Wallaert B, Janin A, Lassalle Ph, et al. Airway-like inflammation of minor salivary gland in bronchial asthma. Am J Respir Crit Med 1994;150:802-9.

8 International Consensus Report on Diagnosis and Treatment of Asthma. National Heart, Lung and Blood Institute, National Institutes of Health, Bethesda, Maryland 20892. Publication no. 92-3091, March 1992. Eur Respir J 1992;5:601-41.

9 Global Initiative for Asthma. NHLBI/WHO Pocket Guide for Asthma Management and Prevention. National Institute of Health, Lung, and Blood
Institute, 1998.

10 Stuart BA. Allergy testing using in vivo and in vitro techniques. Immunol Allergy Clin North Am 1999; 19:35-45.

11 Hijazi Z, Ezeamuzie Cl, Khan M, et al. Characteristics of asthmatic children in Kuwait. J Asthma 2002;39:603-9.

12 Lunn PG, Northrop CA, Northrop AJ. Automated enzymatic assays for the determination of intestinal permeability probes in urine 2. Mannitol. Clin Chim Acta 1989;183:163-70.

13 Northrop CA, Lunn PG, Behrens RH. Automated enzymatic assays for the determination of intestinal permeability probes in the urine. 1. Lactulose and lactose. Clin Chim Acta 1990;187:79-88.

14 COBAS MIRA PLUS. Rorche Diagnostic Systems, Inc., 1080 U.S. HWY \#202, Somerville, NJ 08876-3771.

15 Menzies IS. Transmucosal passage of inert molecules in health and disease. In: Intestinal absorption and secretion. Falk symposium 36. London: MTP Press, 1983:527-43.

16 Anon. Intestinal permeability (editorial). Lancet 1985;2:256-8.

17 Kontou-Karakitsos K, Salvaggio JE, Mathews KP. Comparative nasal absorption of allergens in atopic and nonatopic subjects. J Allergy Clin Immunol 1975;55:241-8.

18 Rudzik R, Clancy RL, Perey DYE, et al. Repopulation with IgA containing cells of bronchial and intestinal lamina propria after transfer of homologous Peyer's patch and bronchial lymphocytes. J Immunol 1975; 114:1599-604.

19 Pike M, Heddle RJ, Boulton P, et al. Increased intestinal permeability in atopic eczema. J Invest Dermatol 1986;86:101-4.

20 Kokkonen J, Simila S, Herva R. Gastrointestinal findings in atopic children. Eur J Pediatr 1980;134:249-54. 